\title{
Continuous stimulation of human glucagon-like peptide-1 (7-36) amide in a mouse model (NOD) delays onset of autoimmune type 1 diabetes
}

\author{
J. Zhang • Y. Tokui • K. Yamagata • J. Kozawa • \\ K. Sayama • H. Iwahashi • K. Okita • M. Miuchi • \\ H. Konya • T. Hamaguchi • M. Namba • I. Shimomura • \\ J-i. Miyagawa
}

Received: 6 April 2007 / Accepted: 14 May 2007 / Published online: 14 July 2007

(C) Springer-Verlag 2007

\begin{abstract}
Aims/hypothesis We examined the effect of glucagon-like peptide-1 (GLP-1) on the development of diabetes and islet morphology in NOD mice by administering GLP-1 to prediabetic mice.

Methods Eight-week-old female NOD mice were infused subcutaneously with human GLP-1 via a mini-osmotic pump for 4 or 8 weeks. In mice treated with GLP-1 for 4 weeks, blood glucose levels and body weight were measured. An intraperitoneal glucose tolerance test (IPGTT) and evaluation of insulitis score were also performed. Beta cell area, proliferation, apoptosis, neogenesis from ducts and subcellular localisation of forkhead box O1 (FOXO1) were examined by histomorphometrical, BrdU-labelling, TUNEL, insulin/cytokeratin and FOXO1/ insulin double-immunostaining methods, respectively.
\end{abstract}

J. Zhang and Y. Tokui contributed equally to this study.

Electronic supplementary material The online version of this article (doi:10.1007/s00125-007-0737-6) contains supplementary material, which is available to authorised users.

J. Zhang $\cdot$ Y. Tokui $\cdot$ K. Yamagata $\cdot$ J. Kozawa $\cdot$ K. Sayama $\cdot$

H. Iwahashi $\cdot$ K. Okita $\cdot$ I. Shimomura

Department of Metabolic Medicine,

Graduate School of Medicine, Osaka University,

Osaka, Japan

M. Miuchi $\cdot$ H. Konya $\cdot$ T. Hamaguchi $\cdot$ M. Namba •

J.-i. Miyagawa $(\triangle)$

Division of Diabetes and Metabolism, Department of Internal

Medicine, Hyogo College of Medicine,

1-1 Mukogawa-cho,

Nishinomiya, Hyogo 663-8501, Japan

e-mail: miyagawa@hyo-med.ac.jp
Results Mice treated with human GLP-1 for 4 weeks had lower blood glucose levels until 2 weeks after completion of treatment, showing improved IPGTT data and insulitis score. This effect continued even after cessation of the treatment. In addition to the increase of beta cell neogenesis, BrdU labelling index was elevated $(0.24$ vs $0.13 \%$, $p<0.001$ ), while apoptosis was suppressed by $54.2 \%$ $(p<0.001)$ in beta cells. Beta cell area was increased in parallel with the translocation of FOXO1 from the nucleus to the cytoplasm. The onset of diabetes was delayed in mice treated with GLP-1 for 4 weeks, while mice treated with GLP-1 for 8 weeks did not develop diabetes by age 21 weeks compared with a $60 \%$ diabetes incidence in control mice at this age.

Conclusions/interpretation Continuous infusion of human GLP-1 to prediabetic NOD mice not only induces beta cell proliferation and neogenesis, but also suppresses beta cell apoptosis and delays the onset of type 1 diabetes.

Keywords Apoptosis · Diabetes mellitus ·

Forkhead box O1 · FOXO1 · GLP-1 .

Glucagon-like peptide-1 · NOD mouse ·

Non-obese diabetic mouse

Abbreviations
$\begin{array}{ll}\text { BrdU L.I. } & \text { percentage of BrdU-positive beta cells } \\ \text { FOXO1 } & \text { forkhead box O1 } \\ \text { GLP-1 } & \text { glucagon-like peptide-1 } \\ \text { ICC } & \text { islet-like cell cluster } \\ \text { IPGTT } & \text { intraperitoneal glucose tolerance test } \\ \text { PI3-K } & \text { phosphatidylinositol 3-kinase } \\ \text { PKB } & \text { protein kinase B }\end{array}$




\section{Introduction}

Glucagon-like peptide-1 (GLP-1) is an insulinotropic peptide that is secreted by the L-cells of the gastrointestinal tract in response to the ingestion of nutrients [1]. GLP-1 not only enhances glucose-dependent insulin secretion and glucose utilisation by the peripheral tissues [2], but also inhibits glucagon secretion, gastric emptying and gastric acid secretion, as well as reducing food intake [3-7]. It has also been demonstrated that GLP-1 agonists stimulate beta cell proliferation and neogenesis in rats, along with increased islet expression of pancreatic and duodenal homeobox gene $1(P d x 1)$, Glut2 (also known as solute carrier family 2 [facilitated glucose transporter], member 2 [Slc2a2]) and glucokinase genes, as well as upregulation of insulin mRNA [8]. The translocation of forkhead box $\mathrm{O} 1$ (FOXOl) from the nucleus to the cytoplasm results in upregulation of $P d x l$ expression through insulin receptor substrate 2 (IRS2)-mediated activation of the phosphatidylinositol 3-kinase (PI3-K)-protein kinase B (PKB) pathway [9]. More recent studies have demonstrated that administration of GLP-1 inhibits beta cell apoptosis via the PI3-K-PKB signalling pathway [10-12]. Importantly, the anti-apoptotic action of GLP-1 has also been demonstrated in freshly isolated human islets [13]. Furthermore, GLP-1 increased the survival of immortalised rodent beta cell lines after challenge with various apoptotic stimuli [12, 14-17]. Because of these actions, GLP-1 offers several potential therapeutic advantages for patients with type 2 diabetes. For type 1 diabetes, treatment combining lisofyline (a synthetic modified methylxanthine) and the GLP-1 analogue exendin-4, with anti-lymphocyte serum and exendin-4 successfully reversed autoimmune diabetes, although treatment with exendin-4 alone was not successful in reversing glycaemic control in NOD mice $[18,19]$. Like human autoimmune type 1 diabetes, the NOD mouse features a prediabetic phase that is characterised by insulitis (mononuclear cell infiltration into islets) without hyperglycaemia. The aim of the present study was to assess how GLP-1 treatment influences the development of diabetes in NOD mice during the prediabetic period.

\section{Methods}

Animals

Our colony of NOD mice was originally purchased from CLEA Japan (Tokyo, Japan) and was maintained on standard laboratory chow under a $12 \mathrm{~h}$ light-dark cycle. The mice were given free access to food and water. They were only fasted on the night before the glucose tolerance test. Institutional guidelines for the care and use of animals were followed. The incidence of diabetes reaches about $80 \%$ in female and $20 \%$ in male mice by 30 weeks of age. The 8-week-old female NOD mice selected for this study were divided into an experimental group and a control group. The protocols for the animal experiments were designed following the Principles of Laboratory Animal Care published by the National Institutes of Health and were approved by the Animal Care and Use Committee of Osaka University Medical School (Osaka, Japan).

\section{GLP-1 treatment and measurement of plasma GLP-1}

The experimental group was treated with GLP-1 and the control group was treated with saline for 4 weeks. Human GLP-1 (7-36) amide (AnaSpec, San Jose, CA, USA) was infused at a constant rate of $1.5 \mathrm{pmol} \mathrm{kg}^{-1} \mathrm{~min}^{-1}$ via a mini-osmotic pump that delivers the solution continuously for up to 28 days (ALZET, model 2004; DURECT, Cupertino, CA, USA) as described previously [20]. To initiate immediate pumping, we placed the pre-filled pumps in $0.8 \%$ saline for at least $40 \mathrm{~h}$ at $37^{\circ} \mathrm{C}$ before implantation. According to the manufacturer's guideline, GLP-1 was dissolved in 5\% acetic acid buffer.

Blood glucose levels and body weight were measured weekly during GLP-1 treatment for 4 weeks. To observe the changes of blood glucose levels after the completion of GLP-1 treatment, we also measured blood glucose levels until the end of monitoring. In a separate experiment, mice were treated with GLP-1 for 8 weeks from 8 weeks of age by replacing the first infusion pump by a second one to further examine the effect of continuous GLP-1 infusion on the development of diabetes.

To confirm the efficacy of continuous GLP-1 infusion, we measured the active plasma GLP-1 concentration in age-matched NOD mice using an ELISA method before and at 2 and 4 weeks after pump implantation. Because at least $200 \mu \mathrm{l}$ of plasma is necessary for one measurement, we used one animal to measure one point concentration. Whole-blood samples were obtained in mice before implantation of pumps $(n=6)$ and 2 and 4 weeks after implantation of the GLP-1 pump ( $n=5$ in each group). The plasma level of GLP-1 was measured with an ELISA kit [GLP-1 (Active) ELISA Kit; Linco Research, St Charles, MO, USA].

Intraperitoneal glucose tolerance test

The intraperitoneal glucose tolerance test (IPGTT) was performed before GLP-1 treatment (at 8 weeks of age) and 4 weeks after the treatment ( $n=6$ in each group). Glucose (2 $\mathrm{g} / \mathrm{kg}$ ) was administered intraperitoneally to conscious animals after an overnight fast. Blood samples were collected from the tail vein into heparinised packed cell 
volume tubes at $0,30,60$ and $120 \mathrm{~min}$, and the blood glucose level was measured with a glucometer (Glutest Ace; Arkray Factory, Shiga, Japan). Plasma insulin levels were measured using a commercial ELISA kit (Glazyme; Sanyo-Kasei, Kyoto, Japan).

Immunohistochemical study

Immunostaining The pancreases were resected from 12week-old female NOD mice after 4 weeks of either GLP-1 or saline infusion ( $n=6$, in each group) and fixed in $10 \%$ phosphate-buffered neutral formalin. Paraffin-embedded sections $(5-7 \mu \mathrm{m}$ thick) cut at $500 \mu \mathrm{m}$ intervals were stained with haematoxylin and eosin to observe mononuclear cell infiltration in and around the islet. Other sections were stained for insulin and BrdU using a polyclonal guinea pig anti-insulin and anti-BrdU antibodies, respectively, and were visualised with diaminobenzidine as described previously [21]. The grade of insulitis was scored on haematoxylin and eosin-stained sections. Approximately 250 islets from three different pancreatic regions $(>300 \mu \mathrm{m}$ interval between each section) were examined in each animal and scored as follows: 0 point for no apparent mononuclear cell infiltration in and around the islets; 1 point for $1-10 \%$ of the area occupied by mononuclear cell infiltration; 2 points for $10-25 \% ; 3$ points for $25-50 \%$; and 4 points for $>50 \%$ occupied [22].

Morphometric analysis We measured the beta cell area on three sections of each pancreas stained for insulin. Morphometric evaluation of the total beta cell area was performed by computer-assisted image analysis (Win RooF software Ver. 5.5; Mitani, Fukui, Japan) using light and immunofluorescence microscopes (Provis AX80T and AX80TR equipped with HDTV system and colour charged-coupling device camera; Olympus, Tokyo, Japan). The area of insulin-positive cells and the total area of the tissue section were evaluated for each section. Then, the percentage beta cell area was determined by calculating the ratio of the area occupied by insulin-positive cells to the total pancreatic area. Since this method is unable to clearly distinguish between beta cells derived from neogenesis and pre-existing beta cells, insulin-positive cells were counted together.

Beta cell replication BrdU is incorporated by newly synthesised DNA in replicating cells. Animals from both groups were injected with BrdU (100 $\mu \mathrm{g} / \mathrm{g}$ body weight, i.p.) (Sigma, St Louis, MO, USA) at $6 \mathrm{~h}$ before the whole pancreas was removed. Sections were double immunostained to detect BrdU and insulin as described above. Then, the percentage of BrdUpositive beta cell nuclei relative to all beta cell nuclei was calculated and was taken to represent the percentage of BrdUpositive beta cells (BrdU L.I.).
Beta cell neogenesis from ductal precursors To evaluate the effect of GLP-1 on beta cell neogenesis, double immunostaining was performed to detect insulin-positive cells and cytokeratin-positive duct cells (see Electronic supplementary material $[\mathrm{ESM}]$ ). Using these sections, we quantified the newly formed beta cells in three different sections of each pancreas from six animals per group. We counted the number of insulin-positive cells in islet-like cell clusters (ICCs) in close contact with ducts, and the number localised in the duct cell lining (beta cells derived from neogenesis). The value for newly formed beta cells was calculated per square $\mathrm{cm}$ of the total pancreatic area.

Localisation of FOXO1 in beta cells Sections from 8- and 12-week-old mice treated with GLP-1 or saline were examined to assess the subcellular localisation of FOXO1 in beta cells after double immunostaining for FOXO1 and insulin. The sections were first incubated overnight with anti-FKHR antibody (1:50) (Cell Signaling Technology, Danvers, MA, USA) at $4^{\circ} \mathrm{C}$ after microwave treatment at $95^{\circ} \mathrm{C}$ for $10 \mathrm{~min}$ in the target retrieval solution (DakoCytomation, Inc., Carpinteria, CA, USA). After washing, sections were incubated with biotinylated goat anti-rabbit immunoglobulin (Vector Laboratories, Burlingame, CA, USA) for $30 \mathrm{~min}$ and FOXO1 was visualised with streptavidin-conjugated Alexa Fluor 488 (Molecular Probes, Eugene, OR, USA). These sections were then immunostained for insulin as described above and were observed under a fluorescence microscope (AX80TR; Olympus).

Beta cell apoptosis The pancreases from 17-week-old mice after treatment with GLP-1 $(n=6)$ or saline $(n=6)$ from 8 to 12 weeks of age were fixed in $10 \%$ phosphate-buffered neutral formalin and paraffin-embedded sections $(5-7 \mu \mathrm{m}$ thick) were cut at $300 \mu \mathrm{m}$ intervals. Apoptosis was detected through labelling DNA strand breaks by the TUNEL method according to the manufacturer's protocol (TaKaRa in situ apoptosis detection kit; TaKaRa Biomedicals, Shiga, Japan), followed by staining for insulin to detect beta cells (for more details see ESM). At least 1,500 to 2,000 beta cell nuclei were counted per pancreas section at a final magnification of $\times 1,000$. A fluorescence microscope was also used to confirm insulin and TUNEL positivity, thus identifying apoptotic beta cells by incubation with rhodamin-conjugated goat anti-guinea pig IgG for insulin.

Monitoring of diabetes mellitus

We monitored the occurrence of diabetes after cessation of the treatment from the age of 12 to 30 weeks in 10 mice per group. In addition, the occurrence of diabetes was further 
examined separately in connection with the 8 weeks of treatment with GLP-1 infusion from the age of 8 to 21 weeks in five mice per group.

The onset of diabetes was assessed by the detection of glucosuria using a glucose test strip (Taisei Medipac, Osaka, Japan) and was confirmed by blood glucose measurement three times per week from the day when positive glucosuria was detected. A blood glucose level $>16.7 \mathrm{mmol} / 1(300 \mathrm{mg} / \mathrm{dl})$ in three consecutive measurements was defined as indicating diabetes (date of onset is the first day).

\section{Statistical analyses}

Data are presented as the mean \pm SEM. Statistical analysis was performed using Student's $t$ test or ANOVA with the ' $n-1$ ' custom hypothesis test, as appropriate. Analysis of morning plasma glucose levels after GLP-1 treatment was performed using the Mann-Whitney $U$ test. The incidence of diabetes was analysed by Kaplan-Meier life table analysis and Cox-Mantel test. A $p$ value of less than 0.05 was considered to indicate statistical significance.

\section{Results}

\section{Plasma GLP-1 level}

The plasma levels of GLP-1 at 2 and 4 weeks after the pump implantation were $77.5 \pm 8.5(n=5)$ and $70.2 \pm 5.8 \mathrm{pg} / \mathrm{ml}(n=6)$, respectively, while plasma GLP-1 before the implantation was $40.2 \pm 3.6 \mathrm{pg} / \mathrm{ml}(n=6)$ under normal feeding conditions. Plasma concentrations of active GLP- 1 at both 2 and 4 weeks after the pump implantation were significantly elevated $(p<0.01)$ and about 1.5-fold higher than before the pump implantation. We therefore considered this delivery system to be appropriate for this experiment.

\section{Improvement of glucose tolerance by GLP-1}

GLP-1 treatment was initiated at 8 weeks of age. GLP-1treated mice had significantly lower glucose levels from 2 weeks onwards during treatment $(4.8 \pm 0.1 \mathrm{mmol} / 1, n=14$, $p<0.001$ vs saline-treated mice $6.6 \pm 0.2 \mathrm{mmol} / 1$, at 4 weeks after the start of GLP-1 treatment) (Fig. 1a). Blood glucose levels were significantly lower in GLP-1 mice than in control mice at 13 weeks of age $(4.7 \pm 0.2 \mathrm{mmol} / 1, n=18$, $p<0.001$ vs saline-treated mice $6.1 \pm 0.2 \mathrm{mmol} / 1$ ) and at 14 weeks of age $(4.8 \pm 0.2 \mathrm{mmol} / 1, n=18, p<0.001$ vs saline-treated mice $6.0 \pm 0.3 \mathrm{mmol} / \mathrm{l})$. This effect also continued at $15(4.9 \pm 0.2 \mathrm{mmol} / \mathrm{l}, p<0.001$ vs saline-treated mice $7.6 \pm 1.3 \mathrm{mmol} / \mathrm{l})$ and 17 weeks of age $(5.9 \pm 0.3 \mathrm{mmol} / \mathrm{l}$, $p<0.05$ vs saline-treated mice $8.7 \pm 1.4 \mathrm{mmol} / \mathrm{l}$ ) (Fig. 1b). These results indicate that GLP-1 improved glycaemic control.

There was no significant difference in body weight between GLP-1- and saline-treated mice (Fig. 1c), so the improved glycaemic control in GLP-1-treated mice did not result from weight loss.

The IPGTT was performed before treatment and at 4 weeks after the treatment. It showed no differences between the two groups before the treatment. However, after 4 weeks of treatment, the blood glucose levels of GLP-1-treated mice were $3.2 \pm 0.04(0 \mathrm{~min}), 10.2 \pm 0.11(30 \mathrm{~min}), 5.4 \pm 0.37$ (60 $\mathrm{min})$ and $4.1 \pm 0.26 \mathrm{mmol} / 1(120 \mathrm{~min})$, whereas those of control mice were $4.0 \pm 0.09,13.5 \pm 0.11,9.3 \pm 0.36$ and $6.5 \pm$ $0.31 \mathrm{mmol} / 1$, respectively ( $n=6$ in each group). Blood glucose levels were significantly lower in GLP-1-treated mice than in saline-treated mice (Fig. 1d). At 4 weeks, the plasma insulin levels of GLP-1-treated mice were $87 \pm 15$ (0 $\mathrm{min}), 337 \pm 14$ (30 min), $226 \pm 41(60 \mathrm{~min})$ and $279 \pm 25$ $\mathrm{pmol} / \mathrm{l}(120 \mathrm{~min})$, whereas the levels of saline-treated mice were $69 \pm 10,224 \pm 24,140 \pm 38$ and $147 \pm 14 \mathrm{pmol} / \mathrm{l}$, respectively. The insulin level in GLP-1-treated mice was significantly higher at 30 and $120 \mathrm{~min}(p<0.01$ for both, $n=6$ ) than in control mice (Fig. 1e).

\section{Morphometric analysis}

The islets seemed to be larger in GLP-1-treated mice (Fig. 2a) than control mice (Fig. 2b) at 12 weeks of age, so we measured the beta cell area in both groups. There was a significant increase in the beta cell area in the GLP-1 group $(0.65 \pm 0.08 \%)$ compared with the saline group $(0.40 \pm 0.04 \%$, $p<0.05, n=6)$ at 4 weeks after GLP-1 treatment (Fig. 2c).

Effect of GLP-1 on beta cell proliferation and neogenesis

There are two possible ways to increase the beta cell mass: the proliferation of pre-existing beta cells, and neogenesis or differentiation from pancreatic stem or duct cells. To examine beta cell proliferation, we evaluated the BrdU L.I. of beta cells by double immunocytochemical staining for insulin and BrdU (Fig. 3a-e). The BrdU L.I. of 12-week-old GLP-1-treated mice $(0.24 \pm 0.02 \%)$ was significantly higher than that of control mice $(0.13 \pm 0.01 \% ; p<0.001, n=5)$ (Fig. 3f).

To evaluate the influence of GLP-1 on beta cell neogenesis, we counted the number of beta cells in the duct epithelium and the number in ICCs budding from the ducts. In NOD mice, the number of newly formed beta cells was more or less increased compared with those of other nondiabetic strains of mice (data not shown). However, the number of newly formed beta cells was further increased in the GLP-1 group $\left(51.5 \pm 5.0 / \mathrm{cm}^{2}\right)$ compared with the control group $\left(30.5 \pm 5.4 / \mathrm{cm}^{2} ; p<0.05, n=5\right)$ (ESM Fig. $1 \mathrm{a}-\mathrm{c}$ ). (The 

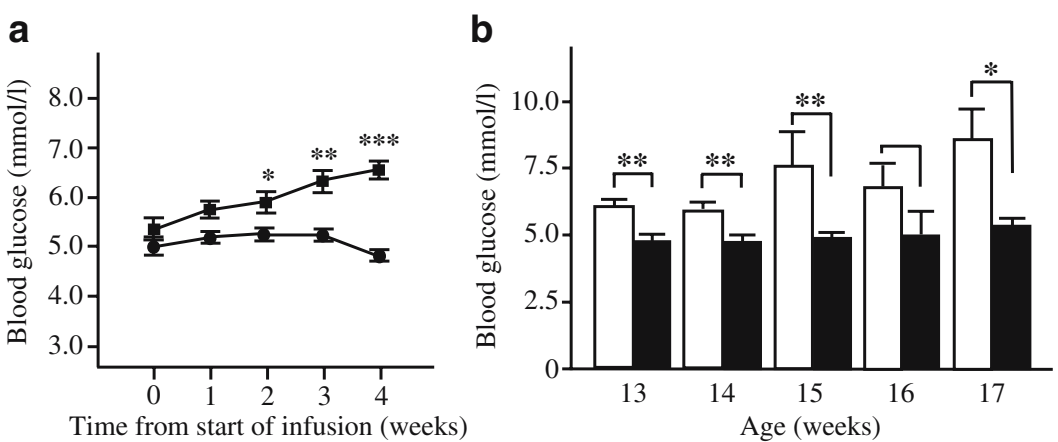

Time from start of infusion (weeks)

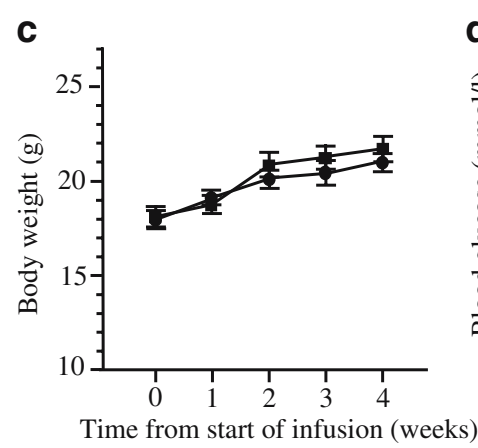

Fig. 1 Effect of GLP-1 on glucose tolerance in NOD mice. a The GLP-1 group (circles, also other panels) had significantly lower plasma glucose levels than the saline group (squares, also other panels) from 2 weeks of treatment onward. b After cessation of the treatment, the GLP-1 group had lower plasma glucose levels than the saline group at 13 and 14 weeks of age, as well as at 15 and 17 weeks. Open bars, saline group; closed bars, GLP-1 group. c Body weight

value is expressed as number of beta cells $/ \mathrm{cm}^{2}$ of the total pancreatic area.)

Localisation of FOXO1 protein and insulin in beta cells

To investigate the changes of subcellular localisation of FOXO1 protein in beta cells after GLP-1 treatment, we examined the localisation of FOXO1 and insulin in the pancreas by immunostaining. FOXO1 was predominantly localised in the nuclei of insulin-positive cells in 8-weekold mice (before treatment) (Fig. $4 \mathrm{a}-\mathrm{c}$ ) and in saline-treated 12-week-old mice (Fig. 4g-i). In contrast, this transcription factor was mainly detected in the cytoplasm of many insulin-positive cells in GLP-1-treated 12-week-old mice (Fig. $4 \mathrm{~d}-\mathrm{f}$ ). Thus, GLP-1 treatment altered the subcellular distribution of FOXO1 and promoted its translocation from the nucleus to the cytoplasm in beta cells.

\section{Effect of GLP-1 on beta cell apoptosis}

We observed a greater number of insulin-positive apoptotic cells in the pancreatic sections of saline-treated mice at 17 weeks of age than in sections from GLP-1-treated mice (Fig. 5a,b). To determine the percentage of TUNELpositive, insulin-containing cells, sections were double-

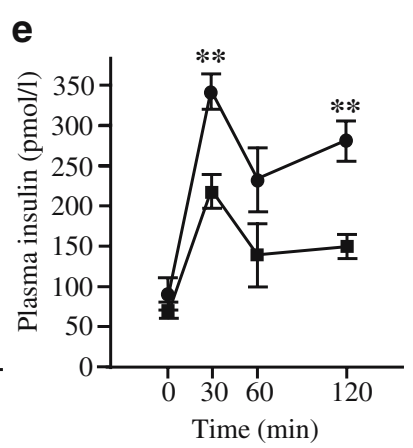

profile during treatment. There was no difference in body weight between the GLP-1 and saline group. d, e IPGTT was performed after 4 weeks of GLP-1 treatment. Plasma glucose (d) and serum insulin levels (e) are shown. The GLP-1 group showed significantly improved glucose tolerance compared with the saline group. Serum insulin levels were significantly higher in the GLP- 1 than in the saline group at 30 and $120 \min * p<0.05, * * p<0.01, * * * p<0.001$

stained for TUNEL and insulin. TUNEL-positive beta cells in saline- and GLP-1-treated NOD mice were $0.24 \pm 0.01$ and $0.11 \pm 0.03 \%$, respectively $(p<0.01, n=6)$. As a result, GLP-1 caused a $54.2 \%$ decrease in the relative number of apoptotic beta cells.

\section{Effect of GLP-1 on insulitis}

To evaluate mononuclear cell infiltration in and around the islets, histological examination of haematoxylin and eosinstained pancreatic sections was done in the GLP-1 and saline groups. The GLP-1-treated 12-week-old NOD mice had significantly more islets with no apparent mononuclear cell infiltration than did the control mice (74.6 vs $51.6 \%$ ). Insulitis in the GLP-1 group at this time point (at scores 2, 3 or 4) was less severe than in the control mice (at scores 2, 3 and 4) (all $p<0.0001, n=4$ ) (ESM Fig. 2). When the mice were 17 weeks old, the degree of each insulitis score showed no significant difference between GLP-1 $(n=5)$ and saline groups $(n=5)$.

\section{Effect of GLP-1 on diabetes}

The occurrence of diabetes was compared between mice treated with GLP-1 $(n=10)$ or saline $(n=10)$ from 8 to 


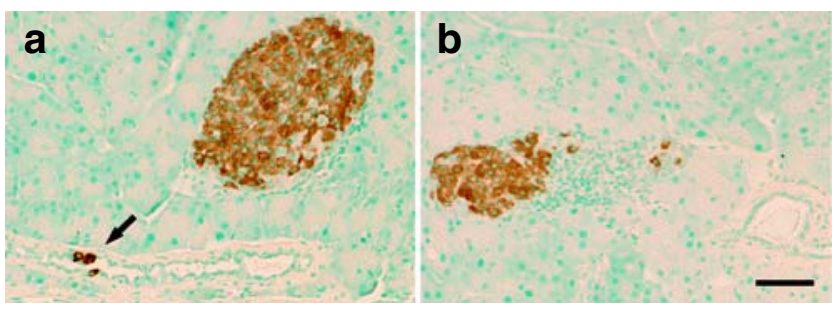

C

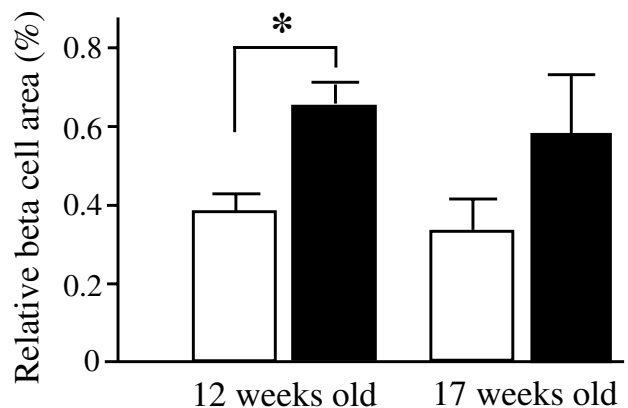

Fig. 2 a, b Immunostaining for insulin in sections from the GLP-1 group and the saline group respectively after 4 weeks of treatment. In the pancreas of GLP-1-treated NOD mouse (a), islets were larger than in that of saline-treated NOD mouse (b). Single beta cell and ICCcontaining insulin-positive cells were seen in and in close contact to the ductal cell lining (arrow) (a). Bar $100 \mu \mathrm{m}$. c Relative beta cell area of the GLP-1 group (closed bars) was larger than that of the saline group (open bars) after 4 weeks of treatment $\left({ }^{*} p<0.05\right)$, but there was no difference in the relative beta cell areas in 17 -week-old mice

30 weeks of age. As shown in Fig. 6a,b, the onset of diabetes was detected from 15 weeks in the saline group, vs 19 weeks in the GLP-1 group. Occurrence of diabetes tended to be suppressed by GLP-1 at 20 weeks of age with $20 \%$ of the GLP-1 group having diabetes versus $50 \%$ of the control group. However, from Kaplan-Meier's life table analysis, the $50 \%$ duration of the non-diabetic period after GLP-1 and saline treatment was 11 and 9 weeks, respec- tively, while the cumulative incidence was not significant at the endpoint of observation by Cox-Mantel test.

When the GLP-1 group was treated for 8 weeks from 8 weeks of age ( $n=5$ in each group), no diabetes was observed in that group, while $60 \%$ of mice in the saline group had developed diabetes by 21 weeks of age. Thus, in both separate experiments, continuous infusion of human GLP-1 appeared to delay or suppress the onset of diabetes.

\section{Discussion}

Glucagon-like peptide-1 is a potent intestinal insulinotropic hormone that augments insulin secretion in rodents as well as in humans with type 1 or type 2 diabetes [23-27]. GLP-1 has been demonstrated to promote the proliferation and differentiation of beta cells in vivo [28] and in vitro [29]. In this study, we demonstrated that the glucose tolerance of NOD mice treated with GLP-1 significantly improved after a glucose load. After treatment with GLP-1 for 2 weeks, the blood glucose level was also significantly lowered. More importantly, the blood glucose level remained lower for 2 weeks after the end of treatment. We also confirmed that the effect of GLP-1 on blood glucose was mainly the result of an increase in beta cell mass. Either proliferation of preexisting beta cells and/or beta cell neogenesis can lead to expansion of the beta cell mass [30]. In our study, 8-weekold NOD prediabetic mice showed early lymphocytic infiltration into the islets. BrdU-positive beta cells were found in islets with various degrees of lymphocytic infiltration in the GLP-1-treated mice and were hardly recognised in the control mice. The BrdU L.I. of beta cells in the GLP-1 group was significantly higher than in the control group. Therefore, we conclude that GLP-1 promoted the proliferation of pre-existing beta cells.
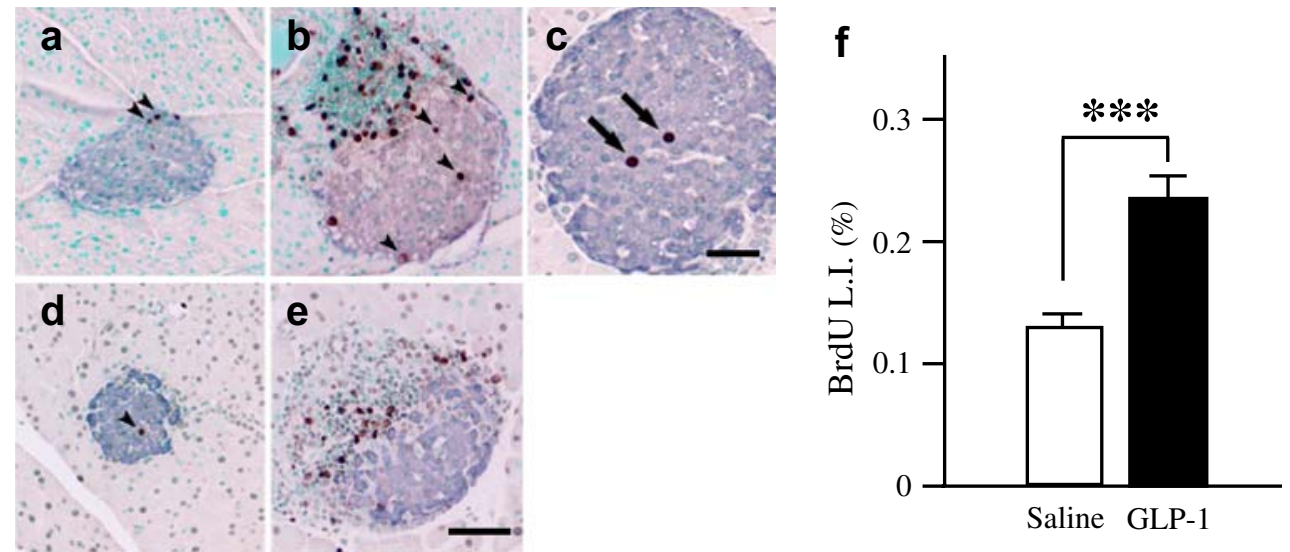

Fig. 3 Effect of GLP-1 on beta cell proliferation. a-e Double immunostaining for BrdU (brown) and insulin (dark grey) in islets with no apparent mononuclear cell infiltration (insulitis) (a, c, and d) and in islets with insulitis (b, e) from pancreases of the GLP-1 group $(\mathbf{a}-\mathbf{c})$ and the saline group $(\mathbf{d}, \mathbf{e})$ after 4 weeks of treatment. BrdU- positive islet cells (arrow heads) were increased in the GLP-1 group. Most of these are insulin-positive (beta cells) as indicated by arrows (c) at higher magnification (bar $30 \mu \mathrm{m}$ ). Bar (e) $50 \mu \mathrm{m}$. f The BrdU L.I. of beta cells after 4 weeks of treatment was significantly higher in the GLP-1 group than in the saline group. ${ }^{* * *} p<0.001, n=6$ 
Fig. 4 Double immunostaining for insulin and FOXO1 in the pancreas from untreated 8-weekold mice (a-c) and from 12week-old mice treated with GLP-1 (d-f) or saline $(\mathbf{g}-\mathbf{i})$. Insulin and $\mathrm{FOXO1}$ protein are identified by red and green fluorescence, respectively. When merged, FOXO1 is recognised predominantly in the nuclei of insulin-positive cells in untreated and saline-treated mice (c, i), while being mainly localised in the cytoplasm of insulin-positive cells in GLP-1 treated mice (f). Bar $100 \mu \mathrm{m}$
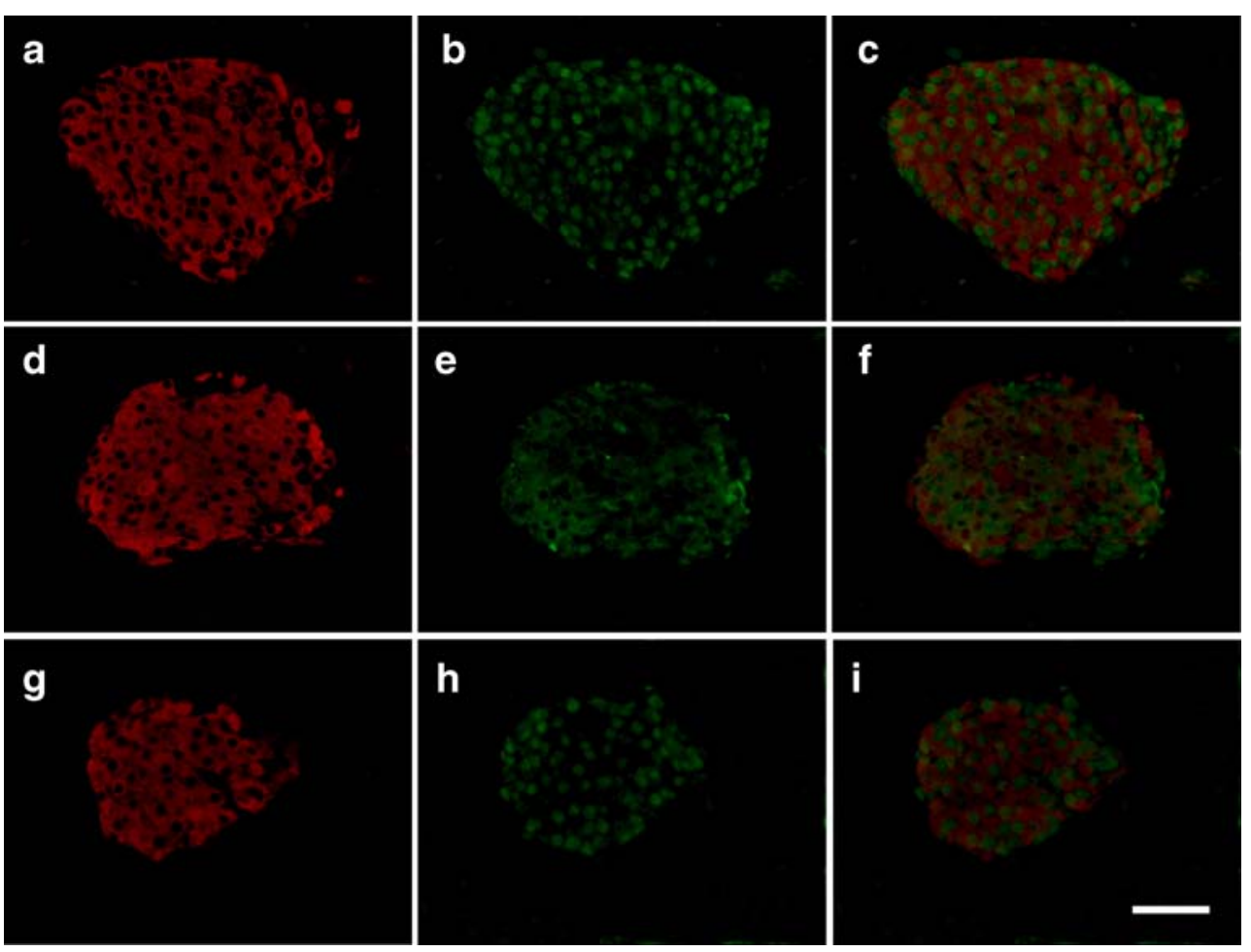

It is generally believed that islet precursor cells exist in the pancreatic ducts [31]. GLP-1 has been shown to induce the production of PDX1 in ducts and the differentiation of duct cells toward insulin-producing cells [32]. In GLP-1treated NOD mice, we found that the number of newly formed beta cells originating from pancreatic ducts was
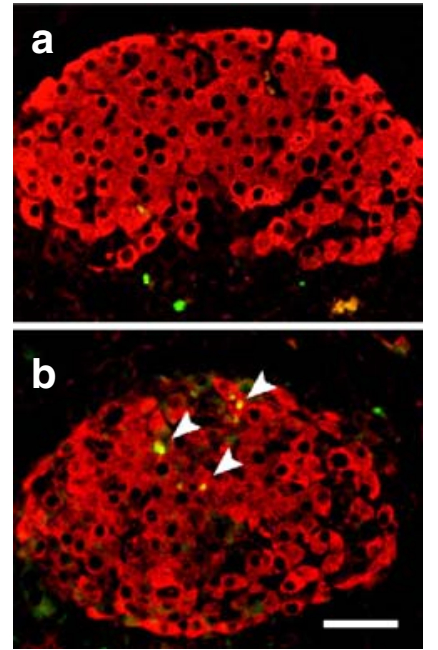

C

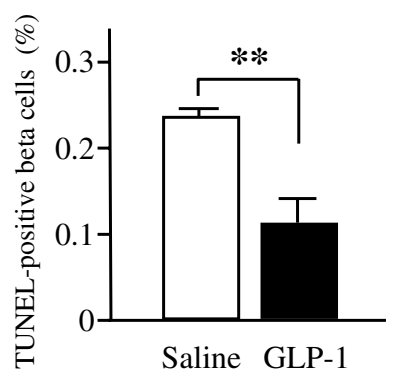

Fig. 5 Effect of GLP-1 on beta cell apoptosis. a, b Double immnunostaining for apoptosis (TUNEL method, green, yellow) and insulin (red) in sections from the GLP-1 group (a) and the saline group (b) at 17 weeks of age. Apoptotic beta cells have TUNELpositive nuclei (arrowheads) surrounded by insulin-positive cytoplasm (red). Such cells were common in the saline group, but rarely seen in the GLP-1 group. Bar $50 \mu \mathrm{m}$. c The percentage of TUNELpositive beta cells in pancreatic sections from 17-week-old mice was lower in the GLP-1 group $(0.11 \pm 0.01 \%)$ than in the saline group $(0.24 \pm 0.01 \%) .{ }^{* *} p<0.01, n=6$ increased. Thus, in addition to the promotion of preexisting beta cell proliferation, GLP-1 stimulated the differentiation of beta cells.

Apart from direct killing of beta cells by autoreactive $\mathrm{T}$ cells, another possible mechanism of beta cell loss in autoimmune type 1 diabetes may be cytokine-induced apoptosis [33, 34]. Recently, it was reported that GLP-1 and other growth factors have an anti-apoptotic effect [11$13,35]$. To investigate whether GLP-1 has an anti-apoptotic effect on beta cells in NOD mice, double staining for insulin and TUNEL was done to directly identify apoptotic cells [36]. Apoptotic beta cells were more easily detected in the islets of control mice. In contrast, such cells were rarely found in the islets of GLP-1-treated mice, although apoptotic cells were seen in the insulin-negative parts in and around the islets. In fact, GLP-1 treatment caused a $54.2 \%$ decrease in apoptotic beta cells compared with the control group. This result suggests that GLP-1 protected beta cells against cytokine-mediated apoptosis. We also demonstrated that the insulitis score became lower and the insulin-positive islet area was larger in GLP-1-treated mice, indicating that the anti-apoptotic activity of GLP-1 might have led to the survival of more beta cells in NOD mice and to maintenance and/or an increase of the beta cell mass.

As reported previously [10, 37, 38], the binding of GLP-1 to its receptor transduces several intracellular signals including the signalling pathways involved in the proliferation and apoptosis of pancreas islet cells. In beta cells, these signals induce the activation of PI3-K and PKB as well as translocation of FOXO1 to the cytoplasm; they also promote 
a
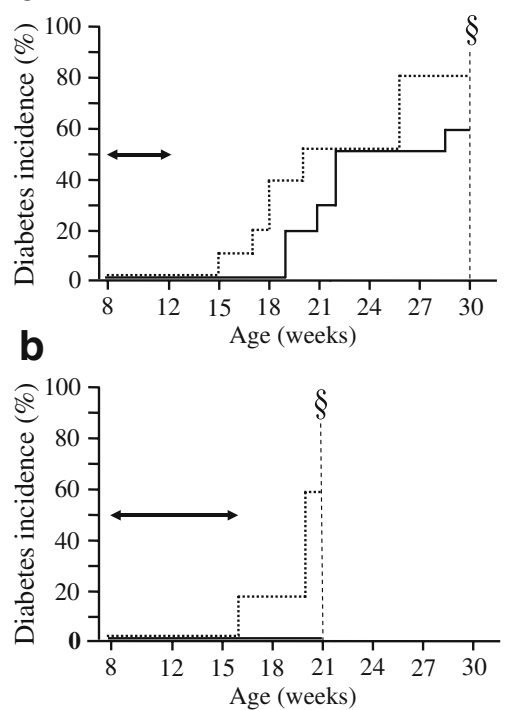

Fig. 6 Cumulative incidence of diabetes during and after 4 weeks (a) and 8 weeks (b) of GLP-1 treatment in NOD mice monitored from 8 weeks of age. In NOD mice treated with GLP-1 or saline for 4 weeks (a), the onset of diabetes was detected from 15 weeks of age in the saline group (dotted line; $n=10$ ), vs 19 weeks in the GLP-1 group (unbroken line; $n=10$ ). Incidence of diabetes in GLP-1- and saline-treated groups was 20 and $50 \%$ respectively at 20 weeks old, and 60 and $80 \%$ respectively at 30 weeks old. The occurrence of diabetes was apparently suppressed during and for 8 weeks after cessation of continuous stimulation with human GLP-1. b In NOD mice treated for 8 weeks with GLP-1 (unbroken line; $n=5$ ) or saline (dotted line; $n=5$ ), diabetes did not occur in the former group, either during GLP-1 treatment, or in the following period of 5 weeks. In contrast, $60 \%$ of the saline-treated mice developed diabetes from the age of 15 to 21 weeks. The difference in diabetes incidence between GLP-1- and saline-treated groups was not statistically significant in either of the experiments according to Kaplan-Meier's life table analysis. Bold, two-arrowed line, duration of GLP-1 or saline treatment. ${ }^{\S}$ Endpoint of the monitoring

cell survival and insulin secretion. The results of a recent study also revealed that the protective effect of GLP-1 on cytokine-induced apoptosis requires activation of PKB [39]. FOXO1 undergoes translocation to the cytoplasm when stimulated by insulin and other growth factors via the activation of PI3-K and PKB, while this forkhead transcription factor is dephosphorylated and localised to the nucleus in the absence of insulin [40]. In the present study, continuous infusion of GLP-1 induced translocation of FOXO1 to the cytoplasm in many beta cells, while FOXO1 was predominantly localised in the nucleus of insulinpositive cells in untreated NOD mice or saline-treated mice. It has been reported that FOXO1 and PDX1 demonstrate mutually exclusive nuclear localisation in beta cells and that nuclear localisation of FOXO1 is associated with weak or negative PDX1 localisation [9]. Therefore, it can be suggested that beta cell proliferation in GLP-1-treated mice was associated with the induction of cytoplasmic FOXO1 translocation, although we were unable to find a clear relationship between the localisation of FOXO1 and PDX1 (data not shown).

In the present study, we administered GLP-1 to prediabetic NOD mice for only 4 weeks. Yet it appeared to delay the development of diabetes. In addition, continuous infusion of GLP-1 for 8 weeks completely suppressed the development of diabetes during and at least until 5 weeks after cessation of the treatment. Our results demonstrate that GLP-1 had both an anti-apoptotic effect on pre-existing beta cells and also promoted the proliferation and/or differentiation of beta cells in NOD mice. In overtly diabetic NOD mice, it has been reported that a GLP-1 analogue (exendin-4) and anti-lymphocyte serum cured diabetes, while exendin-4 alone failed to achieve remission [18]. Although the mechanism leading to the remission of diabetes was not clearly demonstrated in the above experiment, the beta cell mass seemed to be increased by exendin- 4 treatment. In fact, exendin- 4 treatment of $d b / d b$ mice has also been reported to delay the onset of diabetes through a mechanism involving expansion of the functional beta cell mass [10].

Recent treatment of autoimmune type 1 diabetes with islet transplantation has focused attention on cell-based insulin replacement strategies. Together with the current developments in islet transplantation and stem cell therapy, GLP-1 may be a useful agent for regenerative medicine. To date, in vivo effects of GLP-1 on beta cell proliferation and neogenesis have not been demonstrated in the human pancreas, while chronic and continuous stimulation with endogenous GLP-1 is not to be expected because of the short half-life of GLP-1 (2-3 $\mathrm{min})$ due to the existence of the enzyme dipeptidyl peptidase-IV [41]. However, GLP-1 analogues of much longer half-life have been recently developed for the treatment of type 2 diabetes [42]. Longterm stimulation with these analogues might exert the chronic effects of GLP-1 as demonstrated in the present study. Thus, our findings that continuous stimulation with human GLP-1 not only promotes beta cell proliferation and neogenesis, but also protects beta cells from apoptosis in prediabetic NOD mice, may lead to a novel therapeutic approach for type 1 and type 2 diabetes.

Acknowledgements We thank F. Katsube (Department of Internal Medicine and Molecular Science, Graduate School of Medicine, Osaka University) for her excellent technical assistance in immunohistochemistry. This work is supported in part by Grant-in-Aid for Researchers, Hyogo College of Medicine and Grant-in-Aid from the Japan Ministry of Education, Culture and Sports (for J. Miyagawa; no. 18591006).

Duality of interest The authors declare that there is no duality of interest associated with this manuscript. 


\section{References}

1. Kietter TJ, Habener JF (1999) The glucagon-like peptides. Endocr Rev 20:876-913

2. Gromada J, Holst JJ, Rorsman P (1998) Cellular regulation of islet hormone secretion by the incretin hormone glucagon-like peptide-1. Eur J Physiol 435:583-594

3. D'Alessio DA, Fujimoto WY, Ensinck JW (1989) Effects of glucagon-like peptide 1(7-36) on release of insulin glucagon and somatostatin by rat pancreatic islet cell monolayer cultures. Diabetes 38:1534-1538

4. Komatsu R, Matsuyama T, Namba M et al (1989) Glucagonostatic and insulinotropic action of glucagons like peptide 1 (7-36)amide. Diabetes 38:902-905

5. Willms B, Wemer J, Holst JJ, Orskov C, Creutzfeldt W, Nauck MA (1996) Gastric emptying, glucose responses and insulin secretion after a liquid test meal: effect of exogenous glucagonlike peptide 1 (GLP-1) (7-36) amide in type 2 (non-insulin dependent) diabetic patients. J Clin Endocrinol Metab 81:327-332

6. Schjoldager BTG, Mortensen PE, Christiansen J, Orskov C, Holst JJ (1989) GLP-1 (glucagon-like peptide 1) and truncated GLP-1, fragments of human proglucagon, inhibit gastric acid secretion in human. Dig Dis Sci 34:703-708

7. Turton MD, O'Shea D, Gunn I et al (1996) A role for glucagonlike peptide in the central regulation of feeding. Nature 379:69-72

8. Perfetti R, Zhou J, Doyle ME, Egan JM (2000) Glucagon-like peptide-1 induces cell proliferation and pancreatic-duodenum homeobox-1 expression and increases endocrine cell mass in the pancreas of old glucose-intolerant rats. Endocrinology 141:4600-4605

9. Kodama S, Toyonaga T, Kondo T et al (2005) Enhanced expression of PDX-1 and ngn 3 by exendin-4 during beta cell regeneration in STZ-treated mice. Biochem Biophys Res Commun 327:1170-1178

10. Wang Q, Brubaker PL (2002) Glucagon-like peptide-1 treatment delays the onset of diabetes in 8 week-old $\mathrm{db} / \mathrm{db}$ mice. Diabetologia 45:1263-1273

11. Farilla L, Hui H, Bertolotto C, Kang E, Bulotta A, Perfetti R (2002) Glucagon-like peptide-1 promotes islet cell growth and inhibits apoptosis in Zucker diabetic rats. Endocrinology 143:4397-4408

12. Li Y, Hansotia T, Yusta B, Ris F, Halban PA, Drucker DJ (2003) Glucagon-like peptide-1 receptor signaling modulates beta cell apoptosis. J Biol Chem 278:471-478

13. Farilla L, Bulotta A, Hirshbirg B et al (2003) GLP-1 inhibits cell apoptosis and improves glucose responsiveness of freshly isolated human islets. Endocrinology 144:5149-5158

14. Trumper A, Trumper K, Horsch D (2002) Mechanisms of mitogenic and anti-apoptotic signaling by glucose-dependent insulinotropic polypeptide in beta (INS-1)-cells. Endocrinology 174:233-246

15. Hui H, Nourparvar A, Zhao X, Perfetti R (2003) Glucogon-like peptide-1 inhibits apoptosis of insulin-secreting cells via a cyclin 5 -adenosine monophosphate-dependent protein kinase and a phosphatidyl inositol 3-kinase-dependent pathway. Endocrinology 144:1444-1455

16. Ehses JA, Casilla VR, Doty T et al (2003) Glucose-dependent insulinotropic polypeptide promotes beta (INS-1) cell survival via cyclic adenosine monophosphate-mediated caspase-3 inhibition and regulation of p38 mitogen-activated protein kinase. Endocrinology 144:4433-4445

17. Kwon G, Pappan KL, Marshall CA, Schaffer JE, McDaniel ML (2004) Cyclic AMP dose-dependently prevents palmitate-induced apoptosis by both PKA-and cAMP-GEF-dependent pathways in beta cells. J Biol Chem 279:8938-8945

18. Ogawa N, List JF, Habener JF, Maki T (2004) Cure of overt diabetes in NOD mice by transient treatment with anti-lymphocyte serum and exendin-4. Diabetes 53:1700-1705
19. Yang Z, Chen M, Carter JD et al (2006) Combined treatment with lisofyline and exendin-4 reverses autoimmune diabetes. Biochem Biophys Res Commun 344:1017-1022

20. Wang Y, Perfetti R, Greig NH et al (1997) Glucagon-like peptide-1 can reverse the age-related decline in glucose tolerance in rats. J Clin Invest 99:2883-2889

21. Yamamoto K, Miyagawa J, Waguri M et al (2000) Recombinant human betacellulin promotes the neogenesis of beta cell and ameliorates glucose intolerance in mice with diabetes induced by selective alloxan perfusion. Diabetes 49:2021-2027

22. Douglas OS, Han J, Williams J, Yoon J-W, Jun H-S, Ahvazi B (2002) Gamma interferon paradoxically inhibits the development of diabetes in the NOD mouse. J Autoimmun 19:129-137

23. Gutniak M, Orskov C, Holst JJ, Ahren B, Efendic S (1992) Antidiabetogenic effect of glucagon-like peptide(7-36) amide in normal subjects and patients with diabetes mellitus. N Engl J Med 326:1316-1322

24. Nauck MA, Heimesant MM, Orskov C, Holst JJ, Ebert R, Creutzfeldt W (1993) Preserved incretin activity of glucagon-like peptide(7-36) amide but not of synthetic human gastric inhibitory polypeptide in patients with type 2 diabetes mellitus. J Clin Invest 91:301-307

25. Natham DM, Schreiber E, Fogel H, Miisov S, Habener JF (1992) Insulinotropic action of glucagon-like peptide-1 (7-37) in diabetic and nondiabetic subjects. Diabetes Care 15:270-276

26. Nauck MA, Kleine N, Orskov C, Holst JJ, WiIIms B, Creutzfeldt W (1993) Normalization of fasting hyperglycaemia by exogenous glucagon like peptide (7-36) amide in type 2 (non-insulindependent) diabetic patients. Diabetologia 36:741-744

27. Todd JF, Wilding JP, Edwards CM, Khan FA, Ghatei MA, Bloom SR (1997) Glucagon-like peptide-1 (GLP-1): a trial in insulindependent diabetes mellitus. Eur J Clin Invest 27:533-536

28. Tourrel C, Baibe D, Meile M-J, Kergoat M, Portha B (2001) Glucagon-like peptide 1 and exendin- 4 stimulate beta cell neogenesis in streptozotocin-treated new born rats resulting in persistently improved glucose homeostasis at adult age. Diabetes 50:1562-1570

29. Zhou J, Wang X, Pineyro MA, Egan JM (1999) Glucagon-like peptide 1 and exendin-4 convert pancreatic AR42J cells into glucagon- and insulin-producing cells. Diabetes 48:2358-2366

30. Xu G, Stoffers DA, Habener JF, Bonner-Weir S (1999) Exendin-4 stimulates both beta cell replication and neogenesis, resulting in increased beta cell mass and improved glucose tolerance in diabetic rats. Diabetes 48:2270-2276

31. Pictet R, Rutter WJ (1972) Development of the embryonic pancreas. In: Steiner DF, Frenkel N (eds) Handbook of physiology, section 7. American Physiological Society, Washington DC, pp 25-66

32. Brubaker PL, Drucker DJ (2004) Minireview: glucagon-like peptides regulate cell proliferation and apoptosis in the pancreas, gut and central nervous system. Endocrinology 145:2563-2569

33. Mandrup-Poulsen T (2001) Beta-cell apoptosis: stimuli and signaling. Diabetes 50:58-63

34. Uno S, Imagawa A, Okita K et al (2007) Macrophages and dendritic cells infiltrating islets with or without beta cells produce tumor necrosis factor- $\alpha$ in patients with recent-onset type 1 diabetes. Diabetologia 50:596-601

35. Urusova AI, Farilla L, Hui H, D’Amico E, Perfetti R (2004) GLP-1 inhibition of pancreatic islet cell apoptosis. Trends Endocrinol Metab 15:27-33

36. Kurrer MO, Parala SV, Hanson HL, Katz JD (1997) Beta-cell apoptosis in $\mathrm{T}$ cell-mediated autoimmune diabetes. Proc Natl Acad Sci U S A 94:213-218

37. Thorens B (1992) Expression cloning of the pancreatic beta cell receptor for the gluco-incretin hormone glucagon-like peptide-1. Proc Nat Acad Sci U S A 89:8641-8645 
38. Li L, EI-Kholy W, Rhodes CJ, Brubaker PL (2005) Glucagonlike peptide-1 protects beta cells from cytokine-induced apoptosis and necrosis: role of protein kinase B. Diabetologia 48:13391349

39. Accili D (2004) The struggle for mystery in insulin action: from triumvirate to republic. Diabetes 53:1633-1642

40. Kitamura T, Nakae J, Kitamura Y, Kido Y, Accili D (2002) The forkhead transcription factor Foxo1 links insulin signaling to Pdx1 regulation of pancreatic beta cell growth. J Clin Invest 110:18391847

41. Hansen L, Deacon CF, Ørskov C, Holst JJ (2005) Glucagon-like peptide-1-(7-36)amide is transformed to glucagon-like peptide-1(9-36)amide by dipeptidyl peptidase IV in the capillaries supplying the L cells of the porcine intestine. Endocrinology 140:5356-5363

42. Nauck MA, Meier JJ (2005) Glucagon-like peptide 1 and its derivatives in the treatment of diabetes. Regul Pept 128:135-138 